\title{
Transnacionalização do Ensino Superior: Impactos nos Processos Formativos em Psicologia no Brasil
}

\author{
Joao Paulo Macedo \\ Universidade Federal do Piauí, PI, Brasil. \\ Candida Dantas \\ Universidade Federal do Piauí, PI, Brasil. \\ Magda Dimenstein \\ Universidade Federal do Rio Grande do Norte, RN, Brasil. \\ Universidade Federal do Rio Grande do Norte, RN, Brasil
}

Resumo: A expansão da educação superior nos últimos anos aprofundou a hegemonia do setor privado que passou a concentrar significativas fatias do mercado, inclusive com a presença de grupos internacionais operando no Brasil. Trata-se de um fenômeno resultante do alargamento da atuação de grupos financeiros em direção à esfera transnacional com a aquisição e fusão de instituições de ensino superior em todo o mundo. O presente trabalho traça um panorama histórico quanto à formação desses grupos no Brasil acompanhado da análise do impacto desse processo na formação em Psicologia e na organização dos cursos em termos do perfil do egresso, objetivos e estrutura curricular. Utilizou-se de um estudo documental, com base nas informações oficiais da educação superior e dos cursos de Psicologia no Brasil, incluindo os projetos pedagógicos de curso (fontes primárias), além de relatórios financeiros e de gestão dos grupos educacionais e consultorias especializadas em fundos de investimentos (fontes secundárias). Os resultados indicam a movimentação de pelo menos três grandes players transnacionais operando no Brasil: Laureate International Universities, DeVry University e Whitney International University System. Juntos detêm 26 instituições de ensino superior, concentrando-se nas regiões Nordeste (58\%), Sudeste (25\%) e Norte (12,5\%). A Psicologia aparece como curso presente na maioria das IES adquiridas pelos grupos investigados $(n=21)$. Conclui-se que o processo em curso, ao padronizar conteúdos/currículo e homogeneizar determinados processos formativos, pode desvalorizar experiências educacionais locais e aprofundar o descompasso entre os saberes psicológicos e as necessidades sociais do país.

Palavras-chave: Internacionalização, Transnacionalização, Oligopólio, Formação em Psicologia; PPC. 


\title{
The Transnationalization of Higher Education: the Impacts in the Formative Process in Psychology in Brazil
}

\begin{abstract}
The spreading of higher education has enhanced the hegemony on the private sector that has concentrated significant slices of the market, including International groups in Brazil. It is a phenomenon resulting of the expansion of the actions of financial groups towards the transnational sphere with the acquisition and fusion of higher education institutions (HEI) around the world. The present work traces a historical panorama about the formation of these groups in Brazil; it is followed by the analysis of the impact of this process in the formation in Psychology and the organization of the courses in terms of alumni profile, objectives and curricular structure. This is a documental study, based on some official information on higher education and psychology courses in Brazil, including pedagogical projects of the course (Primary sources), as well as financial reports and management of educational groups and specialized consulting in funds (Secondary sources). The results indicate the movement of at least three major transnational players operating in Brazil: Laureate International Universities, DeVry University and Whitney International University System. Together they have 26 higher education institutions, concentrated in the Northeast (58\%), Southeast (25\%) and North (12.5\%). Psychology appears as a course present in most HEI acquired by the analyzed groups $(n=21)$. It is concluded that the current process, by standardizing contents / curriculum and homogenizing certain formative processes, may devalue local educational experiences and deepen the gap between the psychological knowledge and the social necessities of the country.
\end{abstract}

Keywords: Internationalization, Transnationalization, Oligopoly, Training in Psychology, PPC.

\section{Transnacionalización de la Enseñanza Superior: Impactos en los Procesos Formativos en Psicología en Brasil}

Resumen: La expansión de la educación superior en los últimos años profundizó la hegemonía del sector privado que pasó a concentrar significativas rebanadas del mercado, incluso con la presencia de grupos internacionales operando en Brasil. Este fenómeno resulta de la ampliación de la actuación de grupos financieros hacia la esfera transnacional con la adquisición y fusión de instituciones de enseñanza superior (IES) en todo el mundo. Este trabajo presenta un panorama histórico de la formación de estos grupos en Brasil, un análisis del impacto de ese proceso en la formación en Psicología y en la organización de los cursos en términos del perfil del egresado, objetivo y estructuras curriculares. Se utilizó un estudio documental, basado en las informaciones oficiales de la educación superior y de los cursos de Psicología en Brasil, incluyendo los proyectos pedagógicos (fuentes primarias), informes financieros y de gestión de los grupos educativos y consultorías especializadas en fondos de inversiones (fuentes secundarias). Los resultados indican el movimiento de por lo menos tres grandes players transnacionales operando en Brasil: Laureate International Universities, DeVry University y Whitney International University System. Estos detienen 26 instituciones de enseñanza superior, sobretodo en el Nordeste (58\%), el Sudeste (25\%) y el Norte (12,5\%). El curso de Psicología aparece en la mayoría de las IES de los grupos investigados (n $=21$ ). Se concluye que el proceso en curso, al estandarizar contenidos / currículos y homogeneizar determinados procesos formativos, puede devaluar experiencias educativas locales y profundizar el descompás entre los saberes psicológicos y las necesidades sociales del país.

Palabras claves: Internacionalización, Transnacionalización, Oligopolio, Formación en Psicología; PPC. 


\section{Introdução}

O presente artigo propõe situar no âmbito da formação em Psicologia o debate sobre a financeirização e transnacionalização do ensino superior, a partir da conformação de determinadas instituições no Brasil adquiridas por grupos internacionais. Autores como Serafim (2011) entendem as mudanças em curso como uma tendência do setor, espécie de modelo paradigmático "imposto pelo processo de globalização econômica que permeia o mundo contemporâneo" (p. 241). Martins (2015) corrobora da opinião de que a globalização, enquanto fruto da intensificação transfronteiriça de bens, serviços, pessoas, tecnologias, capitais e cultura, também impacta no ensino superior na atualidade, especialmente em tempos de aprofundamento da agenda neoliberal como resposta as "demandas do capitalismo monopolista contemporâneo de predominância financeira" (Mancebo, Silva Junior, \& Schugurensky, 2016, p. 206).

Nessa perspectiva, destaca-se a existência de sistemas nacionais de ensino constituindo uma esfera transnacional no campo da educação, cujo ordenamento baseia-se em procedimentos de gestão empresarial voltados tanto para cultura administrativa das instituições de ensino superior (IES) quanto para sua organização acadêmica, para que possam "trilhar caminhos globais e internacionais; redesenhar seu perfil em direção aos mercados; e desenvolver modalidades de capitalismo acadêmico" (Leite, \& Genro, 2012, p. 764). Assim, além da circulação internacional do conhecimento, a difusão de instituições supranacionais implantou uma nova concepção de universidade que passou a ter "função estratégica no crescimento das economias nacionais e um papel no incremento da competitividade dos países no contexto da economia global" (Martins, 2015, p. 293).

Foi a partir dessas concepções que ocorreu forte expansão de grupos educacionais dotados de modelos de mercantilização e comoditização da educação superior, oriundos dos Estados Unidos, Austrália, Nova Zelândia e Inglaterra, em direção aos países periféricos da Ásia, Oriente Médio, África e América Latina (Martins, 2015; Serafim, 2011).

Botto (2015) refere que esse processo se intensificou, a partir dos anos 1990, quando os sistemas nacionais de educação superior, em âmbito mundial, foram marcados por inúmeras transformações e reformas. Tais mudanças foram induzidas por distintas insti- tuições multilaterais de caráter global, a exemplo da Organização das Nações Unidas para a Educação, a Ciência e a Cultura (Unesco), Banco Mundial (BM), Organização Mundial do Comércio (OMC), como também por meio da formação de blocos econômicos regionais: Organização dos Estados Americanos (OEA), Instituto Internacional da Educação Superior na América Latina e Caribe da Unesco (Iesalc), dentre outras. Tais agências pressionaram os países consorciados a implementarem as seguintes diretrizes: a) transnacionalizar a oferta de serviços de ensino superior sob as regras do mercado financeiro; b) internacionalizar as práticas e recursos educacionais no âmbito do ensino e da pesquisa, fomentando o intercâmbio de estudantes e professores, bem como ações de cooperação acadêmica entre IES, sejam públicas e/ ou privadas.

Para Sudbrack e Negro (2016), as diretrizes propostas pelos organismos acima acabaram por agenciar a educação à ordem econômica, transformando-a em mercadoria voltada para o lucro e o empresariamento. Sob o manto da mundialização do capital avançou-se para transnacionalização do setor com a penetração de grandes corporações multinacionais atuando no ensino superior em termos globais, aquecendo o mercado de fusões e aquisições de instituições de ensino no mercado financeiro internacional.

No caso da internacionalização, apesar do objetivo de impulsionar "o incremento da mobilidade estudantil, o crescimento do ensino a distância, a consolidação da dimensão internacional das atividades de ensino e pesquisa e o surgimento de padrões internacionais de currículos" (Sudbrack, \& Negro, 2016, p. 45), pelo impacto que teve o processo de globalização hegemônica na educação superior, muitas críticas surgiram por entender que tais ações tenham acirrado a competição e a mercadorização do conhecimento, constituindo o que os autores têm denominado já há algum tempo de capitalismo acadêmico (Groppo, 2011).

Por "capitalismo acadêmico" entende-se um regime de engajamento pró-mercado pelas instituições de ensino públicas e privadas em termos mundiais, ao terem que desenvolver, introduzir e mercantilizar produtos de pesquisa e/ou serviços educacionais (desenvolvimento tecnológico, patenteamento de invenções e produtos, materiais de ensino, software e aplicativos educacionais, ou até mesmo modelos curriculares de cursos) para serem adquiri- 
dos no mercado privado, como uma fonte de renda e sustentação financeira dessas instituições (Maués, 2015; Serafim, 2011).

Tais críticas encontram ressonância nas análises de Dale (2007), ao problematizar o processo de internacionalização/financeirização/transnacionalização do ensino superior em curso nos países periféricos ou semiperiféricos, a exemplo do Brasil, considerando o avanço do comércio de serviços de educação superior sob a lógica do mercado mundial e dos chamados grandes players da educação. Sudbrack e Negro (2016) endossam esse debate ao indagarem se se trata de um processo que almeja a internacionalização do conhecimento, cuja preocupação é proporcionar, de maneira solidária, diálogos interculturais e apoio de cooperação acadêmica e científica entre países, ou facilitar o estabelecimento de um mercado mundial de educação terciária resultando numa espécie de colonialismo acadêmico dos países periféricos e semiperiféricos travestido de internacionalização, porém, do tipo lucrativa e privatista. Lima e Maranhão (2011) questionam se a mercadorização do ensino superior pelas relações transnacionais dos players da educação não estaria a intensificar o quadro de semiformação, tal qual proposto por Theodor Adorno, resultando numa formação baseada na adaptação conformada dos alunos à racionalidade instrumental, subsumida à lógica do capital.

Sobre o caso brasileiro, é claro que o processo de internacionalização não é recente. Iniciou de forma induzida pelo Estado para impulsionar o desenvolvimento da expertise científica e tecnológica nas instituições públicas, com o objetivo de responder aos desafios do projeto desenvolvimentista do país. Em seguida, pretendeu estimular a pós-graduação stricto sensu. E mais recentemente, com a expansão do sistema privado do ensino superior, o processo de internacionalização ganhou novos contornos, se afastando da cooperação bilateral e aproximando-se de propostas mercadológicas (Lima, \& Contel, 2011).

Com base nesse panorama de financeirização e transnacionalização do ensino superior, entendemos como pertinente levantar esse debate no âmbito dos estudos sobre formação em Psicologia, com ênfase na necessidade de garantir uma formação contextualizada, ancorada na produção de conhecimentos de acordo com as realidades locais, portanto, coerente com os princípios postos nas Diretrizes Curriculares Nacionais (DCN).
Além disso, Lima e Contel (2011) alertam para urgência da discussão especialmente em contextos em que a cidadania e a soberania política estão cada vez mais difíceis de serem exercidas em função dos interesses econômicos. Ademais, esses mesmos autores reforçam que os poderes legislativo e executivo, no plano nacional, têm tratado a matéria somente como retórica e sem qualquer prioridade em suas agendas. Tal postura dá margem para o esvaziamento de sentidos do que seja a internacionalização da educação, deixando a cargo do mercado explorá-la como produto a ser comercializado (Sudbrack, \& Negro, 2016), posição alinhada, inclusive, aos monopólios da cultura de massas (Maar, 2003).

No Brasil operam, até o momento, três grandes players transnacionais no ensino superior. São eles: Laureate International Universities, DeVry University e Whitney International University System. A Psicologia aparece como um dos cursos ofertados quase sempre na maioria das IES adquiridas por esses grupos, por isso o interesse de tomá-la como objeto desta investigação. Ademais, no rol de princípios e compromissos das referidas DCN, em consonância, em certa medida, com a Carta de Serra Negra, consta que os cursos de Psicologia deveriam garantir uma formação pluralista e fomentar a capacidade crítica dos alunos, inserindo debates sobre as novas demandas da profissão em sintonia com a realidade sociocultural e o contexto regional em que o curso está inserido. Mas, como assegurar tais princípios (e outros) numa realidade em que as IES almejam que os cursos estejam organizados a partir de estruturas curriculares similares ou padronizadas, como por exemplo: os objetivos, da matriz curricular, das metodologias e programas de ensino e, por vezes, do conteúdo das disciplinas e planos de avaliação? De longe este desafio é exclusivo dos cursos dos três grupos já referidos, até mesmo porque a formação em Psicologia está hegemonicamente localizada em IES privadas (81,96\%) (Instituto Nacional de Estudos e Pesquisas Educacionais Anísio Teixeira, 2016)". No entanto, entendemos que o processo de internacionalização dos mercados nacionais torna ainda mais complexa a formação em Psicologia em contextos em que as IES são obrigadas a realizar a gestão acadêmica dos cursos a partir de modelos de gestão empresarial, baseados em enxugamento dos quadros e precarização do trabalho.

Por estes aspectos, este trabalho objetiva, primeiramente, recompor o panorama histórico quanto à 
formação dos grupos transnacionais que operam no Brasil, de modo a explicitar os elementos constitutivos desse processo, bem como caracterizar as instituições de ensino adquiridas por esses grupos em conjunto com os cursos ofertados. Em seguida, para além de uma narrativa histórica ou em termos de um balanço, pretende-se analisar os cursos de Psicologia ofertados, considerando a localização e indicadores avaliativos, os objetivos e o perfil do egresso, além da organização e estrutura curricular, acompanhados do processos formativos e ênfases curriculares.

\section{Método}

Trata-se de uma pesquisa documental, descritiva-exploratória, com base: a) nas informações primárias retiradas dos microdados do Censo do Ensino Superior de 2015 e organizadas em banco de dados próprio; b) nos relatórios financeiros e de gestão dos três grupos internacionais e agências de fundos de investimentos que têm operado no setor educacional mundial, disponíveis nos seus respectivos endereços eletrônicos; c) nos dados secundários apreciados em revistas de finanças e de consultoria e análise de mercado que detalham operações financeiras do setor educacional brasileiro e internacional; d) nos Projetos Pedagógicos dos Cursos de Psicologia (PPC), disponíveis em domínio público, referente aos cursos ofertados nas IES pertencentes aos três grupos que operam no país. O marco temporal para realização do levantamento documental, com exceção dos PPC, considerou o início das atividades dos grupos no Brasil que foi 2001.

Quanto à análise, no caso do material organizado em banco de dados, foi realizada análise de distribuição de frequências. Os documentos em formato de texto passaram por análise interpretativa em profundidade de maneira a identificar e a reconstruir os elementos históricos constitutivos desse processo com base nas referências interpretativas presentes na literatura. Os PPC foram analisados com base em Seixas (2014), que os considera como documentos que representam "tanto uma realidade específica, fruto da história do curso, articulação política para construção do documento e características e especificidades da região que estão inseridos, quanto possuem uma relação estreita com os demais PPC, refletindo uma política mais ampla" (p. 148). Por isso, a importância de considerar esses documentos em nossa estratégia metodo- lógica. De forma sucinta, a análise dos PPC baseou-se nos seguintes elementos: caracterização geral dos cursos (perfil do egresso, objetivos, localização, carga horária, turno de funcionamento e indicadores de avaliação) e estrutura curricular e organização curricular (eixos estruturantes, disciplinas e ênfases). Por fim, sobre os aspectos éticos, mesmo tratando de documentos disponíveis em domínio público, considerou-se o anonimato dos cursos na apresentação das informações.

\section{Resultados}

\section{Panorama da formação de grupos educacionais transnacionais no Brasil}

A aquisição de IES brasileiras por grupos internacionais passou a ser uma realidade com a modificação do marco regulatório da educação superior na década 1990, baseado na Reforma do Aparelho do Estado (Mancebo et al., 2016). Em 2001, o grupo Apollo International, braço externo do holding da University of Phoenix, tornou-se acionista do grupo "Pitágoras", que atuava na educação básica, inclusive, internacionalmente, desde 1979. O propósito desta operação era fortalecer as ações do grupo na educação superior, por meio do aporte de capital e experiência internacional em gestão educacional, particularmente no estado de Minas Gerais, com a fundação da Faculdade Pitágoras. Em 2005, a Apollo International cancelou suas operações no Brasil, ao suspender os investimentos que mantinha fora dos Estados Unidos, obrigando os acionistas do Grupo Pitágoras a repatriar suas participações acionárias, acarretando a saída definitiva da Apollo International do Brasil.

A primeira experiência mais efetiva quanto a operação de grupos transnacionais no país foi realizada pela Laureate International Universities, fundada em 1998, com sede nos Estados Unidos. Trata-se de uma das maiores redes mundiais de educação superior, atuando em 28 países e contando com mais de 80 instituições de ensino que reúnem mais de um milhão de alunos. No Brasil, o grupo Laureate adquiriu até o momento 10 IES, distribuídas em mais de 50 campi, que ofertam ao todo 640 graduações $(89,8 \%$ presenciais e $10,2 \%$ a distância). As IES do grupo estão localizadas em pelo menos oito estados da federação, sendo oito em capitais e quatro em campus fora de sede (Canoas, RS; Feira de Santana, BA; Jaboatão dos Guararapes, PE; e Mossoró, RN). 
A primeira IES a ser adquirida pela Laureate foi a Universidade Anhembi Morumbi, em 2005 (Oliveira, 2009). Atualmente, a IES conta com 127 graduações, com um curso de Psicologia em funcionamento. De acordo com os boletins financeiros levantados pelos relatórios analíticos da CM Consultoria, a transação envolveu o valor de R $\$ 165$ milhões. Para realizar esta operação, a Laureate recebeu cerca de U\$ 150 milhões do International Finance Corporation (IFC), instituição financeira global de propriedade do Banco Mundial. O grupo Laureate ainda é capitalizado pelo fundo de investimento americano Private Equity da Kohlberg Kravis Roberts (KKR \& Co. L.P) (CM Consultoria, 2015).

Os aportes de capital dos dois fundos de investimentos da Laureate deram maior margem de operações no Brasil. No ano de 2007, o grupo comprou a Faculdade dos Guararapes, PE, com 37 graduações, sendo uma de Psicologia; a Business School São Paulo (BSP), SP, que atua no âmbito da pós-graduação; a Faculdade Internacional da Paraíba, PB, com 26 graduações, sendo uma de Psicologia; e a Universidade Potiguar (UNP), RN, com 95 graduações, sendo duas de Psicologia. Em 2008, foram adquiridos o Centro Universitário Uninorte, AM, com 56 graduações, sendo uma de Psicologia; e a Faculdade de Desenvolvimento do Rio Grande do Sul (Fadergs), RS, com 28 graduações, sendo uma de Psicologia. Em 2010, houve a aquisição do Centro Universitário Ritter dos Reis (Uniritter), RS, com 61 graduações, sendo uma de Psicologia; do Centro Universitário Hermínio da Silveira (UNI-IBMR), RJ, com 26 graduações, sendo duas de Psicologia; e da Universidade Salvador (Unifacs), BA, com 72 graduações, sendo duas de Psicologia. Em 2012 foi a vez do Centro de Desenvolvimento Empresarial - Cedepe Business School, PE, também voltada para o âmbito da pós-graduação. Em 2013, o grupo comprou os $41 \%$ restantes da Anhembi Morumbi em um negócio estimado em 400 milhões de reais. Em 2014, ocorreu a aquisição do Complexo Educacional Faculdades Metropolitanas Unidades (FMU) em São Paulo pelo valor de R 1 bilhão. A IES possui 112 graduações, sendo uma de Psicologia (CM Consultoria, 2015).

O segundo grupo a operar no Brasil é a Whitney International University System, fundado em 2005, com sede nos EUA. Além de atuar em solo americano está presente na América Latina, no Norte da África e Oriente Médio, dentre outros. Somente na América Latina, continente que concentra maior força, conta com duas IES e 151 graduações (85,4\% presenciais e $14,6 \%$ a distância). Iniciou as atividades no Brasil em 2006, capitalizado pelo fundo de investimento americano Best Associates na ordem de $\mathrm{R} \$ 23$ milhões para aquisição da Faculdade Jorge Amado (Unijorge) em Salvador, BA, com 70 graduações, sendo uma de Psicologia. Em 2011, o grupo adquiriu a Universidade Veiga de Almeida, na capital do Rio de Janeiro, com 81 graduações, sendo duas de Psicologia. Mais recentemente, em 2014, a Whitney International chegou a fechar acordo para fusão com o grupo brasileiro Ânima Educação, pelo montante de mais de R 1 bilhão. Porém, o negócio foi desfeito em 2015, depois das mudanças nas regras na concessão do financiamento estudantil pelo Governo Federal (Whitney University System, \& Anima Educação, (s.d.); Estadão, 2015).

O terceiro grupo transnacional em operação no Brasil é a DeVry University. Trata-se de uma rede internacional de ensino superior de capital aberto, com sede em Chicago (EUA), com pouco mais de 80 anos de existência, localizado em 90 campi em mais de 50 países. Iniciou suas atividades em escolas com cursos de eletrônica e computação nos anos 1980. Ao realizar novas aquisições diversificou sua atuação nas áreas de saúde e de negócios. Atualmente a DeVry Education Group é uma holding de sete empresas educacionais estadunidenses: Advanced Academics, Becker Professional Education, Carrington College, Chamberlain College of Nursing, DeVry University, Keller Graduate School of Managemente Ross University. As ações são negociadas principalmente na Bolsa de Valores de New York, e outras como a Bolsa de Berlim, de Dusseldorf, de Frankfurt e de German Composite, todas na Alemanha (Pinheiro, 2014).

Em 2009, a DeVry abre escritório administrativo no Brasil para iniciar suas atividades no país. Em pouco tempo passou a operar em 11 estados da federação, somando ainda o Distrito Federal. Ao todo são 17 IES que ofertam 264 graduações (98,5\% e 1,5\% a distância). As IES pertencentes ao grupo estão localizadas nas capitais brasileiras $(n=12)$, sendo três em cidades do interior (Campinas, SP; Caruaru, PE; e Imperatriz, MA).

As primeiras aquisições da DeVry University no Brasil foram em 2009: Faculdade Área-1, BA, com sete graduações; Faculdade Ruy Barbosa, BA, com 28 graduações, sendo uma de Psicologia; e Faculdade Nordeste (Fanor), CE, com 44 graduações, sendo uma de Psicologia. Em 2012, o Grupo adquiriu a Faculdade 
Boa Viagem, BA, com 44 graduações, sendo uma de Psicologia, e a Faculdade do Vale do Ipojucá (Unifavip), $\mathrm{PE}$, com 30 graduações, sendo uma de Psicologia. Em 2013, foi a vez da Faculdade Diferencial Integral, PI, com 14 graduações, sendo uma de Psicologia. Em 2014, foram adquiridas: a Faculdade Ideal (FACI), PA, com 13 graduações; a Faculdade DeVry/João Pessoa (Faculdade Motiva), PB, com quatro graduações; a Faculdade DeVry/São Luís, MA, com quatro graduações; e a Faculdade Martha Falcão, AM, com 21 graduações, sendo uma de Psicologia. Em 2015, tiveram as seguintes aquisições: Instituto Brasileiro de Mercado de Capitais (Ibmec), distribuído por: Rio de Janeiro (13 graduações), Minas Gerais (oito graduações) e Distrito Federal (quatro graduações); Faculdade Damásio, SP, com uma graduação; e Faculdade Integrada Metropolitana de Campinas, SP, com 18 graduações. Mais recentemente, em 2016, o grupo comprou da Faculdade de Imperatriz (Facimp), MA, com 11 graduações. Todas essas operações foram possíveis em função do aporte de capital dos fundos de investimentos estran- geiros na DeVry, especialmente pela BlackRock Institutional Trust Company, com a movimentação direta de US\$ 4,32 trilhões; pela The Vanguard Group, com a movimentação direta de aproximadamente US $\$ 2$ trilhões; além da Dimensional Fund Advisors, com menor participação em termos de aportes de capital.

Na Tabela 1 apesentamos uma síntese das IES e cursos dos três grupos investigados.

Observa-se que o grupo Laureate conta com maior número de cursos, apesar de a DeVry possuir maior número de IES. Os cursos ofertados pelas instituições adquiridas por este último grupo estão concentrados em maior número em faculdades isoladas (88,65\%) e centros universitários (11,4\%), enquanto que na Laureate o destaque é para universidades $(45,9 \%)$ e centros universitários $(39,8 \%)$. A Whitney International, apesar de contar com somente duas instituições (universidade e centro universitário), concentra um número expressivo de graduações (n = 151) se comparado à DeVry, que conta com 17 IES e 264 graduações.

\section{Tabela 1}

Síntese do Panorama das IES e Cursos de Graduação (no geral) ofertados pelos Grupos educacionais transnacionais que atuam no Brasil.

\begin{tabular}{|c|c|c|c|c|c|}
\hline & \multicolumn{5}{|c|}{ Variáveis } \\
\hline & & \multicolumn{2}{|c|}{ IES } & \multicolumn{2}{|c|}{ Graduações } \\
\hline & & $\mathrm{N}$ & $\%$ & $\mathrm{~N}$ & $\%$ \\
\hline \multirow[t]{4}{*}{ Grupos } & Laureate & 10 & 34,5 & 640 & 60,7 \\
\hline & DeVry & 17 & 58,2 & 264 & 25,0 \\
\hline & Whitney & 2 & 6,3 & 151 & 14,3 \\
\hline & Total & 29 & 100 & 1.055 & 100 \\
\hline \multirow[t]{4}{*}{ Organização Acadêmica } & Faculdade & 19 & 65,5 & 325 & 30,8 \\
\hline & Centro Universitário & 6 & 20,6 & 355 & 33,6 \\
\hline & Universidade & 4 & 13,9 & 375 & 35,5 \\
\hline & Total & 29 & 100 & 1.055 & 100 \\
\hline \multirow[t]{6}{*}{ Regiões } & Norte & 3 & 10,3 & 90 & 8,5 \\
\hline & Nordeste & 14 & 48,3 & 486 & 46,1 \\
\hline & Centro Oeste & 1 & 3,4 & 4 & 0,4 \\
\hline & Sudeste & 9 & 31,1 & 386 & 36,6 \\
\hline & Sul & 2 & 6,9 & 89 & 8,4 \\
\hline & Total & 29 & 100 & 1.055 & 100 \\
\hline \multirow[t]{3}{*}{ Localização } & Capital & 22 & 75,86 & 898 & 85,1 \\
\hline & Interior & 7 & 24,14 & 157 & 14,9 \\
\hline & Total & 29 & 100 & 1.055 & 100 \\
\hline
\end{tabular}

Fonte: Elaboração própria a partir dos microdados do Censo do Ensino Superior 2015. 
Quanto ao escopo de abrangência da presença dos grupos no país, estão mais fortemente concentrados nas regiões Nordeste e Sudeste, com destaque para os estados de São Paulo e Bahia, e com presença mais tímida no Centro-oeste. As graduações do grupo Laureate estão localizadas na região Sudeste $(41,4 \%)$, com destaque para o estado de São Paulo, seguido da região Nordeste $(35,9 \%)$, com destaque para o Rio Grande do Norte e Bahia. Por outro lado, o grupo Laureate não tem atuação na região Centro-oeste. No caso da DeVry, as graduações estão mais fortemente concentradas na região Nordeste $(70,5 \%)$, principalmente nos estados do Pernambuco, Ceará e Bahia, respectivamente. Merece destaque a região Norte, pois reúne $12,9 \%$ das graduações do grupo, enquanto na região Sul não há operações da DeVryaté o momento. A Whitney International, conforme referido anteriormente, está presente basicamente nas regiões Sudeste (53,6\%), particularmente no estado do Rio de Janeiro, e Nordeste $(46,4 \%)$ no estado da Bahia.

Nota-se com a apresentação desse cenário, que, do montante do número de IES e cursos em funcionamento no país ${ }^{1}$, os três grupos detêm as fatias de 1,4\% e 4,6\% das instituições e dos cursos privados. Aparentemente sugere pouco impacto, porém, trata-se de um mercado relativamente novo que vem sendo explorado há pouco mais de 10 anos e que movimenta grandes somas de investimentos. Segundo a consultora financeira KPMG (2012), em 2006, registrou-se cerca de 18 IES associadas a grupos educacionais (nacionais e transnacionais) que concentravam $26,1 \%$ dos alunos do setor. No período entre 2007 e 2011, o mercado de fusões e aquisições no setor educacional realizou pelo menos 102 transações, com uma movimentação financeira de mais de $\mathrm{R} \$ 5$ bilhões. Percebe-se, portanto, que se trata de um mercado em ascensão, considerando que os grandes players do setor privado que atuam no Brasil, concentraram 39\% do mercado de alunos e $34 \%$ do faturamento líquido do setor (CM Consultoria, 2015).

Para muitos autores, o próprio processo de expansão do ensino superior no Brasil ocorrido nos últimos anos aqueceu as operações nacionais e transnacionais de grupos educacionais financeiros, de capital aberto, capitalizados por fundos estrangeiros que atuam como acionistas dessas empresas
(Carvalho, 2013; Mancebo, Vale, \& Martins, 2015). Outro aspecto que contribuiu foi o aumento da demanda por formação superior no país na última década, incluindo um número expressivo de pessoas egressas do ensino médio que até então não tinham acesso ao nível superior, além do aumento do poder de renda, ganho e consumo da população (Instituto Brasileiro de Geografia e Estatística, 2015).

De acordo com Chaves (2010) e Leher (2010), esse conjunto de fatores possibilitou maior fôlego e confiança para que o setor privado de ensino superior assumisse novos contornos, no sentido de trilhar os caminhos da internacionalização dos mercados nacionais redesenhando o perfil das instituições de ensino. Para Cislaghi (2012), um dos fatores que mais impulsionou o setor a organizar-se em grupos econômicos foi o aprofundamento da privatização do fundo público via transferência direta/indireta de recursos para o setor privado, acompanhado da monetarização da política educacional no Brasil. Tavares (2014) fortalece esse argumento ao referir que a disputa do fundo público pelo setor privado tornou a educação superior fronteira promissora de exploração do mercado financeiro. A destinação do montante de recursos do poder público para compra de vagas no setor privado, por meio do Programa Universidade para Todos (ProUni), a partir de isenções e desonerações tributárias, com a provisão inicial de $\mathrm{R} \$ 177$ milhões em 2005, chegando ao pico em 2012 no valor de $\mathrm{R} \$ 890$ milhões, e passando para a casa de $\mathrm{R} \$ 625$ milhões em 2014, como também a partir do financiamento direto aos estudantes por meio do Fundo de Financiamento Estudantil (Fies), que entre o período 2003-2014 passou de $\mathrm{R} \$ 1,1$ bilhão para $\mathrm{R} \$ 12,5$ bilhões (Reis, 2016), indica o quanto nos países periféricos e semiperiféricos, por força das agências multilaterais, a mercadorização da educação contou com o apoio dos seus governantes. É nesse sentido que devemos lembrar de Martins (2015), ao visualizar a educação como estratégica no cenário de crescimento das economias nacionais. Porém, como refere o autor, isso ocorreu não por via do conhecimento e da ciência e tecnologia produzidos pelas instituições de ensino, mas pelo valor que estas passaram a ter no mercado financeiro global (private equity), em função do número de matrículas que possuem.

\footnotetext{
${ }^{1}$ De acordo com o Censo do Ensino Superior de 2015, constam 2.364 IES, sendo 2.069 privadas, e 33.501 cursos, sendo 22.732 privados (Instituto Nacional de Estudos e Pesquisas Educacionais Anísio Teixeira, 2016).
} 
A entrada desses grupos transnacionais no mercado brasileiro acarretou na reestruturação organizativa das IES adquiridas, considerando a tradição e expertise que esses grupos têm na área de gestão financeira e acadêmica (Mancebo et al., 2015). Assim, salvo algumas exceções, conforme vimos no balanço aqui realizado, os grupos passaram a adquirir IES de médio e pequeno porte, com indicadores acadêmicos razoáveis (instituições e cursos) e potencial de mercado, porém, com baixa poder de penetrabilidade e nível de governança gerencial, além dos muitos passivos que possuíam. Uma vez incorporadas aos grupos sofrem um intenso processo de reestruturação com a implantação de um modelo de organização gerencial, financeiro e acadêmico, acompanhado por estratégias de marketing e vendas, no objetivo de consolidar a marca da IES e do grupo educacional como uma instituição de massa (mensalidades mais baratas e grande número de alunos). Assim, miram na oferta de cursos populares e atrativos, com instalações multicampi e ganhos de escala e lucratividade (Mancebo et al., 2015).

Em resumo, vimos nesse primeiro bloco que a internacionalização dos mercados educacionais de ensino superior no Brasil aqui reportada reúne os elementos constitutivos de um processo que certamente apresenta características de distanciamento do debate sobre a internacionalização do conhecimento. A internacionalização do conhecimento, como vimos, trata-se de um debate pautado pela solidariedade acadêmica que está, em certa parte, na agenda de muitas universidades brasileiras, com maior ênfase no âmbito da pós-graduação stricto sensu e que também tem alcançado a graduação com ações de mobilidade internacional de estudantes, alavancado pelo Programa Ciências Sem Fronteiras do Ministério da Ciência, Tecnologia e Inovação (MCTI) e do Ministério da Educação (MEC).

A internacionalização aqui reportada no âmbito privado apresenta interesses marcadamente mercantis, o que aprofunda o risco das instituições se configurarem como meras produtoras de profissionais e conhecimentos práticos funcionais ao mercado. Entendemos ser este um aspecto problemático, que requer maior debate, ainda mais em um sistema de ensino superior voltado hegemonicamente para o mercado e massificado, pois as repercussões podem se caracterizar como danosas e reforça a posição do Brasil na divisão internacional do trabalho em relação a produção do conhecimento acadêmico (geopolítica do conhecimento) em que o "estudante é consumidor, os saberes são mercadorias e o professor um assalariado que ensina" (Mollis, 2006, p. 87. Tradução nossa).

\section{O perfil dos cursos de Psicologia adquiridos pelos grupos transnacionais}

Conforme referido anteriormente, os três grupos que atuam no Brasil adquiriram, nos últimos 10 anos, 29 instituições de ensino, totalizando 22 cursos de Psicologia, o que proporcionalmente representa $3,92 \%$ dos cursos registrados no MEC. Esses cursos estão distribuídos nas regiões Nordeste $(n=12)$, Sudeste $(n=6)$, Sul $(n=2)$ e Norte $(n=2)$.

\section{Tabela 2}

Localização e indicadores dos cursos de Psicologia ofertados pelos Grupos Educacionais Estrangeiros que operam no mercado brasileiro.

\begin{tabular}{|c|c|c|c|c|c|}
\hline \multirow{2}{*}{ Grupos } & \multirow{2}{*}{$\begin{array}{l}\text { Cursos de } \\
\text { Psicologia }\end{array}$} & \multirow{2}{*}{ Capital } & \multirow{2}{*}{ Interior } & \multicolumn{2}{|c|}{ Indicadores de Curso } \\
\hline & & & & IGC & ENADE \\
\hline Laureate & 13 & 10 & $\begin{array}{l}\text { 2-Grande Porte } \\
1 \text { - Médio Porte }\end{array}$ & $\begin{array}{l}\text { Nota } 4 \text { - } 2 \\
\text { Nota } 3 \text { - } 8\end{array}$ & $\begin{array}{l}\text { Nota } 4 \text { - } 1 \\
\text { Nota } 3 \text { - } 7 \\
\text { Nota } 2 \text { - } 1 \\
\text { S/Aval. - } 4\end{array}$ \\
\hline DeVry & 6 & 5 & 1 - Médio Grande Porte & Nota 3 - 6 & $\begin{array}{l}\text { Nota } 3 \text { - } 3 \\
\text { Nota } 2 \text { - } 2 \\
\text { S/Aval. - } 1\end{array}$ \\
\hline Whitney & 3 & 2 & 1-Médio Porte & Nota 3 - 2 & $\begin{array}{l}\text { Nota } 4 \text { - } 1 \\
\text { Nota } 3 \text { - } 2\end{array}$ \\
\hline
\end{tabular}

Fonte: Elaboração própria a partir dos microdados do Censo do Ensino Superior 2015. 
Tabela 3

Distribuição das disciplinas dos cursos de Psicologia com base no quadro dos eixos estruturantes das DCN para os cursos de Psicologia.

\begin{tabular}{|c|c|c|c|c|c|c|c|c|c|c|c|c|c|}
\hline \multirow[t]{2}{*}{ Grupo } & \multirow{2}{*}{$\begin{array}{c}\text { Compon. } \\
\text { Curriculares } \\
\text { IES }\end{array}$} & \multicolumn{2}{|c|}{$\begin{array}{l}\text { Eixo I: } \\
\text { Fund. } \\
\text { Epistem. e } \\
\text { Históricos }\end{array}$} & \multicolumn{2}{|c|}{$\begin{array}{c}\text { Eixo II: } \\
\text { Fund. Teórico } \\
\text { Metodológicos }\end{array}$} & \multicolumn{2}{|c|}{$\begin{array}{c}\text { Eixo III: } \\
\text { Procedimentos } \\
\text { Investigação } \\
\text { Científica e } \\
\text { Prática } \\
\end{array}$} & \multicolumn{2}{|c|}{$\begin{array}{l}\text { Eixo IV: } \\
\text { Fenômenos } \\
\text { e Processos } \\
\text { Psicológicos }\end{array}$} & \multicolumn{2}{|c|}{$\begin{array}{l}\text { Eixo V: } \\
\text { Interfaces } \\
\text { com } \\
\text { Campos } \\
\text { Afins }\end{array}$} & \multicolumn{2}{|c|}{$\begin{array}{l}\text { Eixo VI: } \\
\text { Práticas } \\
\text { Profissionais }\end{array}$} \\
\hline & & $\mathrm{N}$ & $\%$ & $\mathrm{~N}$ & $\%$ & $\mathrm{~N}$ & $\%$ & $\mathrm{~N}$ & $\%$ & $\mathrm{~N}$ & $\%$ & $\mathrm{~N}$ & $\%$ \\
\hline \multirow[t]{6}{*}{ DeVry } & Curso 1 & 4 & $7,40 \%$ & 24 & $44.40 \%$ & 10 & $18,50 \%$ & 5 & $9,25 \%$ & 9 & $16,60 \%$ & 18 & $33,30 \%$ \\
\hline & Curso 2 & 4 & $7,40 \%$ & 24 & $44.40 \%$ & 10 & $18,50 \%$ & 5 & $9,25 \%$ & 9 & $16,60 \%$ & 18 & $33,30 \%$ \\
\hline & Curso 3 & 4 & $7,40 \%$ & 24 & $44.40 \%$ & 10 & $18,50 \%$ & 5 & $9,25 \%$ & 9 & $16,60 \%$ & 18 & $33,30 \%$ \\
\hline & Curso 4 & 4 & $7,40 \%$ & 24 & $44.40 \%$ & 10 & $18,50 \%$ & 5 & $9,25 \%$ & 9 & $16,60 \%$ & 18 & $33,30 \%$ \\
\hline & Curso 5 & 4 & $7,40 \%$ & 24 & $44.40 \%$ & 10 & $18,50 \%$ & 5 & $9,25 \%$ & 9 & $16,60 \%$ & 18 & $33,30 \%$ \\
\hline & Curso 6 & 4 & $7,40 \%$ & 24 & $44.40 \%$ & 10 & $18,50 \%$ & 5 & $9,25 \%$ & 9 & $16,60 \%$ & 18 & $33,30 \%$ \\
\hline \multirow[t]{10}{*}{ Laureate } & Curso 1 & 3 & $5,08 \%$ & 39 & $66,10 \%$ & 13 & $22,0 \%$ & 6 & $10,10 \%$ & 9 & $15,20 \%$ & 11 & $18.60 \%$ \\
\hline & Curso 2 & 3 & $5,08 \%$ & 39 & $66,10 \%$ & 13 & $22,0 \%$ & 6 & $10,10 \%$ & 9 & $15,20 \%$ & 11 & $18,60 \%$ \\
\hline & Curso 3 & 3 & $5,60 \%$ & 20 & $69,81 \%$ & 7 & $13,20 \%$ & 4 & $7,54 \%$ & 5 & $9,40 \%$ & 6 & $11,30 \%$ \\
\hline & Curso 4 & 3 & $5,66 \%$ & 29 & $54,70 \%$ & 8 & $15,09 \%$ & 4 & $7,54 \%$ & 5 & $9,43 \%$ & 6 & $11,32 \%$ \\
\hline & Curso 5 & 2 & $3,30 \%$ & 35 & $58,30 \%$ & 10 & $16,60 \%$ & 10 & $16,6 \%$ & 6 & $10,0 \%$ & 7 & $11,60 \%$ \\
\hline & Curso 6 & 2 & $3,03 \%$ & 41 & $62,20 \%$ & 16 & $24,20 \%$ & 5 & $7,57 \%$ & 10 & $15,15 \%$ & 9 & $13,60 \%$ \\
\hline & Curso 7 & 2 & $3,22 \%$ & 37 & $59,60 \%$ & 13 & $20,90 \%$ & 4 & $6,40 \%$ & 7 & $11,20 \%$ & 11 & $17,74 \%$ \\
\hline & Curso 8 & 5 & $7,93 \%$ & 43 & $68,25 \%$ & 9 & $14,20 \%$ & 4 & $6,30 \%$ & 5 & $7,93 \%$ & 9 & $14,20 \%$ \\
\hline & Curso 9 & 2 & $2,98 \%$ & 32 & $47,70 \%$ & 11 & $16,40 \%$ & 7 & $10,44 \%$ & 7 & $10,44 \%$ & 12 & $18,46 \%$ \\
\hline & Curso 10 & 3 & $4,61 \%$ & 37 & $56,90 \%$ & 12 & $18,46 \%$ & 4 & $6,10 \%$ & 6 & $9,23 \%$ & 12 & $18,46 \%$ \\
\hline \multirow[t]{2}{*}{ Whitney } & Curso 1 & 2 & $2,85 \%$ & 37 & $52,80 \%$ & 12 & $17,14 \%$ & 8 & $11,40 \%$ & 8 & $11,40 \%$ & 15 & $21,40 \%$ \\
\hline & Curso 2 & 3 & $2,40 \%$ & 38 & $52,77 \%$ & 14 & $19,44 \%$ & 6 & $8,33 \%$ & 15 & $20,83 \%$ & 10 & $13,88 \%$ \\
\hline
\end{tabular}

Fonte: Elaboração baseada na análise dos PPC de Psicologia localizados em domínio público, inspirado em Seixas (2014).

Pelos dados constantes na Tabela 2, as IES vinculadas aos grupos e que ofertam cursos de Psicologia contam com Índice Geral de Cursos (IGC) variando entre 3 e 4. Quanto a nota do último Exame Nacional de Desempenho de Estudantes (Enade), 54,5\% dos cursos pertencentes aos grupos alcançaram nota $3 \mathrm{e}$ $9 \%$ nota 4 . Sendo que alguns cursos vinculados a Laureate e a DeVry apresentaram conceito insatisfatório ou não participaram do ciclo avaliativo do Enade. É comum o uso do resultado das avaliações do ensino superior pelo setor privado como recurso de marketing para captação de alunos. Sobre a localização dos cursos, $66,7 \%$ funcionam nas capitais e $33,3 \%$ em localidades do interior, notadamente em municípios de médio porte ou superior, pois contam com maior potencial de mercado consumidor.

No geral são cursos que contam com carga horária mínima de 4.000 horas, conforme estabelece as
DCN, sendo que o funcionamento ocorre na maioria nos turnos matutino e noturno visando atender perfis de estudantes distintos, principalmente aqueles que trabalham e estudam. Juntos, os 22 cursos oferecem um total de 2.960 vagas por ano para entrada de novos alunos: Laureate (1.380 vagas/ano), a DeVry (780 vagas/ano) e a Whitney (800 vagas/ano).

Quanto aos objetivos, os cursos investigados não diferem dos demais, se comparados às análises de Seixas (2014) sobre os diferentes currículos de Psicologia no Brasil. Os PPC aqui analisados indicam oferecerem uma formação "plural", "global" e "generalista", com enfoque "interdisciplinar", aliando "teoria e prática" e "ações de pesquisa", de maneira a permitir que o estudante faça escolhas dentre as diversas áreas da Psicologia e atue sempre com base na ética profissional. Sobre o perfil dos egressos, também não diferem dos demais com descrições mais gerais ou 
mais específicas do perfil a ser alcançado por essas formações. Indicam que o egresso deve ser capaz de integrar o saber psicológico com aspectos científicos, sociais e políticos; utilizar os conhecimentos psicológicos adquiridos em diversos contextos com qualidade técnica e rigor ético; analisar, articular, discriminar e criticar os diversos enfoques teóricos do campo da Psicologia; atuar junto a equipes multiprofissionais; planejar e administrar serviços de Psicologia; buscar aprimoramento e capacitação contínua; dentre outros. Assim, ainda com base em Seixas (2014), este parece ser um discurso mais aceito entre os PPC de Psicologia, considerando o alinhamento com o texto das DCN, pois é recorrente a menção desses termos independentemente se a IES é pública ou privada, ou se é faculdade, centro universitário ou universidade. Assim, a parte introdutória dos documentos acaba assumindo uma mesma retórica, alinhando-se a aquilo que é esperado pelos critérios de avaliação para o (re)credenciamento dos cursos pelo MEC, porém, por vezes, encontra-se dissociada da arquitetura curricular ou de como esta é colocada em prática pelos processos formativos de cada curso.

Quanto à estrutura e à organização curricular, de acordo com as DCN, as matrizes curriculares devem abranger conhecimentos, competências e habilidades em pelo menos seis eixos estruturantes: I - Fundamentos epistemológicos e históricos; II Fundamentos teórico-metodológicos; III - Procedimentos para a investigação científica e a prática profissional; IV - Fenômenos e processos psicológicos; V - Interfaces com campos afins do conhecimento; VI - Práticas profissionais.

No que diz respeito às matrizes curriculares analisadas, observou-se que os cursos ofertados pelas diferentes IES pertencentes à DeVry, inclusive localizadas em diferentes regiões do país, independentemente de estar situada nas capitais ou interior, trabalham com a mesma estrutura curricular, organizada em quatro níveis: a) introdutório - disciplinas dos eixos: fundamentos epistemológicos e históricos e interface com campos afins do conhecimento; b) intermediário disciplinas dos eixos: fundamentos epistemológicos, fundamentos teórico-metodológicos, fenômenos e processos psicológicos e procedimentos de investigação científica e prática; c) pré-profissionalizante - disciplinas dos eixos: fundamentos teórico-metodológicos, fenômenos e processos psicológicos, e procedimentos de investigação científica e prática; d) profissionalizante - disciplinas do eixo: práticas profissionais. No caso da Laureate e da Whitney, cada curso trabalha a partir de uma estrutura curricular própria, apesar de manterem forte semelhanças quanto às disciplinas e organização curricular entre os cursos de cada grupo.

Ao considerar a distribuição das disciplinas a partir dos eixos estruturantes dos currículos que conseguimos acesso $(n=18)$, disponíveis em domínio público, verifica-se quadro apresentado na Tabela 3.

Ao localizarmos as disciplinas dos cursos nos eixos estruturantes em Psicologia, observa-se, semelhante ao reportado por Seixas (2014), que houve uma menor distribuição entre os eixos I, IV, V e VI. Tal aspecto preocupa, considerando que as disciplinas desses eixos possibilitam ao formando: a) maior contato com o conhecimento das bases epistemológicas que fundamentam a construção do saber psicológico; b) compreensão ampliada dos fenômenos e processos psicológicos a partir de diversas concepções teóricas e metodológicas, inclusive em interface com outras áreas do conhecimento, assegurando uma compreensão integral, crítica e contextualizada dos fenômenos; c) além de assegurar competências para inserção e atuação profissional em diferentes contextos institucionais e sociais. O pouco investimento dos currículos nesses eixos, no entendimento de Campos (2014), pode fragilizar posturas críticas e reflexivas na formação dos psicólogos no sentido de não compreenderem os embates históricos e o campo de tensão e disputa entre as diferentes concepções de objeto e método, além das diferentes visões de mundo, de sujeito e de sociedade que permeiam a construção do saber psicológico e seus projetos de profissão. Ora, esses cursos não estariam a reforçar as tradicionais bases formativas em Psicologia ao investir em disciplinas e conteúdos pouco implicados no desenvolvimento da capacidade crítica do aluno e que reconheça e valorize os múltiplos olhares sobre a complexidade do fenômeno psicológico, inclusive a partir de diferentes realidades socioculturais e contextos regionais?

Por outro lado, na análise realizada, sobressaíram disciplinas relativas aos eixos II - fundamentos teórico-metodológicos $(59,6 \%)$ e III - procedimentos para investigação científica e a prática (18,7\%), pois apresentam maiores médias entre o conjunto das demais. No primeiro caso foram disciplinas com enfoque mais teórico-conteudista, que tratam sobre os domínios já consolidados da Psicologia desde 
o currículo mínimo de 1962, enquanto no eixo III foram disciplinas de caráter mais técnico, voltadas para o domínio de instrumentos e estratégias de avaliação e intervenção profissional, além daquelas relacionadas a atividade de pesquisa, porém, com menor peso. Tais aspectos reafirmam o risco de a formação em Psicologia manter-se fragmentada em conteúdos orientados pelos especialismos e tecnicismos que atendem muito mais ao imediatismo do mercado, com profissionais orientados em suas formações com um peso maior para os conhecimentos práticos da profissão, bastantes funcionais ao mercado, a partir de uma instrumentalização conservadora, em detrimento da aquisição de competências e habilidades acompanhadas da reflexão epistemológica e ético-política de "articular o como-fazer ao porquê-fazer” (Ferreira Neto, 2010, p. 139).

De forma mais específica, enquanto os currículos dos cursos do grupo DeVry apresentam menor peso em relação ao eixo II (44,4\%), cujas disciplinas são de enfoque mais teórico-conteudista, se comparado aos cursos dos demais grupos, percebe-se maior peso no eixo VI das práticas profissionais (33,3\%), o que pode ser indício de um curso com propriedades profissionalizantes demandadas pelo mercado e direcionado para prática e intervenção. Por outro lado, os cursos do grupo Laureate apresentam menor peso no eixo das práticas profissionais (15,3\%), chegando inclusive apresentar cursos com perfil bem mais teórico, com uma formação voltada para os fundamentos da Psicologia $(69,81 \%)$. Poderíamos tomar esse dado como um analisador da lógica gerencial-financeira dos grandes players da educação de também interferirem (flexibilizarem) na organização dos currículos e oferta de disciplinas para diminuir custos e aumentar os ganhos de suas empresas? Certamente este é um aspecto que precisa ser melhor analisado por estudos futuros. Porém, é fato que os componentes curriculares do eixo práticas profissionais impactam bem mais na planilha de custeio de cada matriz curricular, considerando que demandam maior número de professores-supervisores de estágio em função do desdobramento de carga horária e de turmas, a depender da quantidade alunos matriculados, como também de supervisores de campo e/ou preceptores de serviços. O Conselho Regional de Psicologia de São Paulo, por exemplo, recomenda que o PPC em Psicologia deve garantir tempo suficiente para supervisão dos estagiários, com grupos de 10 alunos para um mínimo de quatro horas/aula de supervisão semanal e o mínimo de $1 / 2$ hora/aula no caso de supervisões individuais (Conselho Regonal de Psicologia São Paulo, 2010).

Ademais, observa-se que no eixo V - "Interface com campos afins do conhecimento", há maior presença de disciplinas do tipo: "Planejamento de Carreira", "Aconselhamento e desenvolvimento de carreira", "Carreira, liderança e trabalho em equipe", "Empreendedorismo", "Oficina de Liderança”, “Trajetórias Profissionais e Carreiras", "Coaching”. Chama atenção a valorização desse perfil de disciplinas e conteúdos ofertados nos cursos, inclusive como elemento de marketing ao referirem que ofertam formações preocupadas em melhorar e ajudar os futuros profissionais a já saberem como melhor gerenciar e "turbinar" sua carreira e trajetória profissional, em detrimento de componentes curriculares relacionados ao fortalecimento do diálogo com outros campos de saber propulsores de um pensamento crítico, inclusive adensando o olhar sobre as bases epistemológicas da Psicologia e a sua relação com a sociedade e a cultura. Tal fato traduz o direcionamento que determinadas formações têm tomado na cena global com a reprodução de conhecimentos voltados para o fundamento empresarial, por meio de uma estrutura que se orienta por meio da lógica do mercado, redesenhando, como pode, os perfis profissionais ofertados pelos cursos desses grupos (Serafim, 2011).

Entendemos que tanto a incorporação de disciplinas voltadas para o mercado, quanto a replicação das estruturas/componentes curriculares entre os cursos que compõem as IES de um mesmo grupo, bem como a implantação de programas e serviços de gestão acadêmica que o processo de transnacionalização impõe são ações que aprofundam a aquisição de competências para responder às exigências do mercado, espécie de mantra tornado verdade pelo processo de globalização que permeia o mundo contemporâneo. Tal fato pode evidenciar, de um lado, características de uma semiformação tal qual referida anteriormente, ao fortalecer a reprodução continuada do tecnicismo da profissão; e do outro coexistir em um mesmo curso "projetos profissionais com diferentes fidelidades ideopolíticas", podendo tanto implicar estudantes e professores em torno de um projeto ético-político "que se articule com projetos societários mais amplos e que apontem para transformação estrutural da sociedade capitalista", ou reafirmar a manutenção e reprodução do status quo (Yamamoto, 2012, p. 15). 
Aprofundando um pouco mais sobre o risco que o processo de internacionalização dos mercados educacionais nacionais podem trazer para a padronização dos serviços oferecidos pelo setor, Sampaio (2014) indica pelo menos duas características que os grandes grupos educacionais de capital aberto, especialmente os transnacionalizados, têm adotado em sua estrutura acadêmico-gerencial no Brasil, que são: a) "padronização pedagógica e de conteúdos nos cursos que oferecem para públicos distintos em diferentes regiões do país"; e b) "a adoção de modelos gerenciais que combinam uma gestão estratégica centralizada - desvinculada do corpo acadêmico - e gerências táticas descentralizadas, exercidas pela figura do "'coordenador de curso'” (p. 50). As duas medidas podem ser entendidas, a partir da perspectiva de Verhine e Freitas (2012), como forças homogeneizadoras que são apresentadas pela racionalidade acadêmico-gerencial e financeira como estratégia para obtenção de lucro e resultados satisfatórios para o mercado.

Homogeneizar o perfil, as competências a serem adquiridas, a matriz curricular, disciplinas, inclusive oferecendo parte do conteúdo a distância, são algumas das estratégias para alcançar um único sistema de ensino e maior controle acadêmico-gerencial e financeiro por parte dos grupos educacionais, que resultam em ganhos em escala (Santos, Guimarães-Iosif, \& Chaves, 2013). Como efeito, observa-se maior tendência dos cursos em ofertar formações voltadas para as competências técnicas, sob o risco de transformar a formação superior em apenas instrumento de qualificação de mão de obra especializada.

Quanto às ênfases curriculares constantes na matriz dos cursos oferecidos pelos grupos investigados, destacam-se as relacionadas aos processos clíni$\cos (n=13)$, de gestão e trabalho $(n=5)$, de prevenção e promoção da saúde $(n=7)$, Psicologia social comunitária e institucional $(n=7)$ e processos educativos $(n=3)$. Por questões de mercado, é compreensível que esses cursos estejam voltados para a área clínica, reforçando a imagem da Psicologia no seu fazer clínico tradicional, enquanto campo de representação forte que a população tem sobre a profissão, inclusive para fazer o curso ser consumido no mercado da educação superior. Por outro lado, o aparecimento das ênfases "Psicologia e processos de prevenção e promoção da saúde" e "Psicologia social comunitária e institucional" reflete as atuais tendências da profissão no Brasil que é a abertura de postos de trabalho no âmbito das políticas sociais, notadamente na Saúde e Assistência Social. Porém, quando recorremos aos componentes curriculares dos cursos para subsidiar conhecimentos e a atuação nas políticas sociais, percebe-se fragilidades dos currículos investigados, além de reforçarem a dicotomia indivíduo e sociedade na Psicologia, e dialogarem pouco com a realidade em que esses cursos estão inseridos (Silva, 2005).

\section{Considerações finais}

O fortalecimento do setor privado tem sido a principal marca do ensino superior desde a Reforma Universitária de 1968. Mas surgiu um elemento novo as primeiras décadas do século XXI: o protagonismo dos fundos de investimentos e a formação de oligopólios na educação. O quadro de desregulamentação da legislação abrindo o setor para o capital financeiro e o papel do Estado atuando na transferência do fundo público para o setor privado nos últimos anos favoreceram a concentração e a centralização de capitais, tornando a educação um dos ramos mais rentáveis no setor de serviços.

A entrada de grupos estrangeiros no mercado educacional nacional abriu, portanto, um novo ciclo no setor com o aquecimento do mercado de fusões e aquisições. Como efeito, as IES vêm se internacionalizando estruturalmente, tanto pela participação de capital estrangeiro quanto com a implantação dos processos de gestão financeira e acadêmica, inclusive de materiais didáticos, acompanhado da promessa da formação e vivência internacional. As aquisições das IES pelos grupos representam nichos estratégicos do mercado. Desse modo, as IES adquiridas são transformadas em instituições de massa, com foco em determinados perfis de alunos, por meio de cursos populares, atrativos, que possibilitem ganhos de escala e rentabilidade. Assim, compreende-se que a internacionalização do ensino superior no Brasil, pelo menos no setor privado é marcada pelos interesses do mercado com ações muito tímidas em torno da solidariedade acadêmica, voltada para formação e qualificação de recursos humanos via mobilidade acadêmica e produção e circulação internacional do conhecimento.

É fato que a internacionalização dos mercados nacionais de ensino superior abriu novo debate sobre o risco de interferências na educação brasileira. O alerta é quanto à perda da autonomia educacional, a desnacionalização e a descontextualização do ensino, resultando no aprofundamento de modalidades de 
ensino a distância e semipresenciais e o investimento de cursos voltados para áreas específicas do mercado, inclusive atendendo à certificação em massa com a destinação de profissionais a empregos precários e mal pagos. Outro aspecto é quanto ao risco de um maior alinhamento entre os currículos de um mesmo grupo, tornando-os mais homogêneos com a padronização dos conteúdos e dos processos formativos, além da pouca diversificação de experiências educacionais locais. Não podemos esquecer do momento atual, pós impeachment da presidente eleita Dilma Rousseff e a implementação das primeiras medidas do governo ilegítimo de Michel Temer, que intensifica a ofensiva neoliberal no país, cujos impactos no ensino superior precisarão ser avaliados.

Sobre a Psicologia, como vimos, trata-se de um curso presente na quase totalidade das IES adquiridas pelos três grupos que operam no Brasil. Entende-se que, pela atratividade que representa, tanto por ser um curso que exige baixos custos de implantação, quanto pela forte cultura psicológica já enraizada na sociedade brasileira ao reconhecer a profissão como dotada da capacidade para resolver problemas de ajustamento de comportamento e/ ou de personalidade, incluindo aspectos de ordem emocional, cognitivo e moral que se apresentam nas mais diversas esferas da vida, mas também voltada para ações de autoconhecimento, autoapri- moramento profissional e realização pessoal, acaba sendo um curso bastante procurado nos processos seletivos nacionais.

Os riscos referidos alhures, no caso dos processos formativos em Psicologia, podem gerar certos descompassos com os princípios firmados pelas DCN em Psicologia que sugerem uma formação contextualizada e que valorize a produção de conhecimentos mediante os contextos locais. Nesse sentido, há a necessidade de superar determinadas formas de atuação hegemônicas e que estão "massificadas" na profissão. E por isso são reforçadoras de tecnicismos e que têm como base uma formação descontextualizada, cujo modelo hegemônico desconsidera as realidades locais, as características da população, as necessidades de saúde e assistência social, as atividades produtivas, as relações políticas e vulnerabilidades psicossociais em diferentes contextos. Conhecer o cenário social, político, econômico e cultural onde os cursos são implantados, e onde os profissionais estão atuando, detectando as demandas regionais e sociais feitas à Psicologia parece óbvio, mas não é o que se tem detectado na realidade. Apesar dos limites deste estudo, ressaltamos a importância do tema e a necessidade de aprofundamento com novas pesquisas dimensionando inclusive a vivência desse processo por parte dos alunos, professores e gestores de cursos vinculados aos grupos transnacionais que operam no Brasil.

\section{Referências}

Botto, M. (2015). La transnacionalización de la educación superior:i qué papel juegan los nuevos regionalismos en la difusión de estas ideas? El caso del MERCOSUR (1992-2012) en perspectiva comparada. Revista Iberoamericana de Educación Superior, 6(16), 90-109. Recuperado de http://www.scielo.org.mx/pdf/ries/v6n16/v6n16a5.pdf

Campos, M. (2014). Políticas de formação em psicologia em Goiás: diretrizes curriculares e projetos pedagógicos (Tese de doutorado). Faculdade de Educação, Universidade Federal de Goiânia, Goiânia, GO.

Carvalho,C.H.A. (2013).Amercantilização da educação superiorbrasileira easestratégias demercado dasinstituições lucrativas. Revista Brasileira de Educação, 18(54), 761-776. https://doi.org/10.1590/S1413-24782013000300013

Chaves, V. L. J. (2010). Expansão da privatização/mercantilização do ensino superior brasileiro: a formação dos oligopólios. Educação \& Sociedade, 31(111), 481-500. https://doi.org/10.1590/S0101-73302010000200010

Cislaghi, F. J. (2012). Financiamento do ensino superior no Brasil: novos e antigos mecanismo de privatização do fundo público. In S. Evilasio, E. Behring, I. Boschetti, S. Granemann (Orgs.), Financeiração: fundo público e política social (pp. 261-284). São Paulo, SP: Cortez.

CM Consultoria. (2015). Fusões e aquisições no ensino superior brasileiro. Recuperado de http://www.cmconsultoria.com.br/novo/cmnow/fusoesaquisicoes

Conselho Regional de Psicologia São Paulo - CRP SP. (2010). Organização e funcionamento dos estágios obrigatórios. In: Conselho Regional de Psicologia São Paulo - CRP SP. Recomendações aos Serviços-Escola de Psicologia do Estado de São Paulo: compromisso ético para a formação de psicólogos. Recuperado de http://www.crpsp.org.br/ portal/comunicacao/servicos_escola/fr_organizacao.aspx 
Dale, R. (2007). Globalization and the rescalling of educational governance. In: C. A. Torres, \& A. Teododo (Eds.), Critique and utopia: new developments in the sociology of education in the twenty-first century (pp. 25-42). Lanham, MD: Rowman and Littlefield.

Estadão. (2015, 23 de abril). Anima desfaz negócio bilionário com americana Whitney. Recuperado de http://economia.estadao.com.br/noticias/geral,anima-desfaz-negocio-bilionario-com-americana-whitney-imp-,1674430

Ferreira Neto, J. L. (2010). Uma genealogia da formação do psicólogo brasileiro. Memorandum, 18, 130-142. Recuperado de http://pablo.deassis.net.br/wp-content/uploads/genealogia-formacao-psicologo-brasileiro.pdf

Groppo, L. A. (2011). Da universidade autônoma ao ensino superior operacional: considerações sobre a crise da universidade e a crise do Estado nacional. Avaliação (Campinas), 16(1), 37-55. https://doi.org/10.1590/S1414-40772011000100003

Instituto Brasileiro de Geografia e Estatística - IBGE. (2015). Coordenação de População e Indicadores Sociais. Sintese de indicadores sociais: uma análise das condições de vida da população brasileira (Estudos \& Pesquisas. Informaçao demográfica e socioeconômica, vol. 36). Rio de Janeiro, RJ: o autor. Recuperado de http://biblioteca. ibge.gov.br/visualizacao/livros/liv95011.pdf

Instituto Nacional de Estudos e Pesquisas Educacionais Anísio Teixeira - INEP. (2016). Sinopses estatísticas da educação superior. Brasília, DF: o autor. Recuperado de http:// portal.inep.gov.br/superior-censosuperior-sinopse

KPMG Corporate Finance. (2012). Pesquisa de fusões e aquisições $2012-2^{\circ}$ trimestre: espelho das transações realizadas no Brasil. 2012. Recuperado de https://www.kpmg.com/BR/PT/Estudos_Analises/artigosepublicacoes/ Documents/Fusoes\%20e\%20Aquisicoes/2012/FA-4otrim-2012.pdf

Leher, R. (2010). Crise do capital e questão social. Estudos do Trabalho, 3(6), 17-35. Recuperado em 23 de setembro 2016 de http://www.estudosdotrabalho.org/4RevistaRET6.pdf

Leite, D., \& Genro, M. E. H. (2012). Avaliação e internacionalização da educação superior: Quo vadis América Latina?. Avaliação (Campinas), 17(3), 763-785. https://doi.org/10.1590/S1414-40772012000300009

Lima, M. C., \& Contel, F. B. (2011). Internacionalização da Educação Superior: nações ativas, nações passivas e geopolíticas do conhecimento. São Paulo, SP: Alameda.

Lima, M. C., \& Maranhão, C. M. S. A. (2011). Políticas curriculares da internacionalização do ensino superior: multiculturalismo ou semiformação. Ensaio: Avaliação e Políticas Públicas em Educação, 19(72), 575-598. https://doi.org/10.1590/S0104-40362011000400007

Maar, W. L. (2003). Adorno, semiformação e educação. Educação \& Sociedade, 24(83), 459-475. https://doi.org/10.1590/S0101-73302003000200008

Mancebo, D., Vale, A. A., \& Martins, T. B. (2015). Políticas de expansão da educação superior no Brasil 1995-2010. Revista Brasileira de Educação, 20(60), 31-50. https://doi.org/10.1590/S1413-24782015206003

Mancebo, D., Silva Junior, J. R., \& Schugurensky, D. (2016). A educação superior no Brasil diante da mundialização do capital. Educação em Revista, 32(4), 205-225. https:// doi.org/10.1590/0102-4698162033

Martins, C. B. (2015). Notas sobre a formação de um sistema transnacional de ensino superior. Caderno CRH, 28(74), 291-308. https:// doi.org/10.1590/S0103-49792015000200004

Maués, O. C. (2015). A expansão e a internacionalização da educação superior. Anais da 37a Reunião Nacional da ANPEd, UFSC, Florianópolis. Recuperado de http://www.anped.org.br/sites/default/files/trabalho-gt11-3897.pdf

Mollis, M. (2006). Geopolítica del saber: biografías recientes de las universidades latino-americanas. In: H. Vessuri, Universidad e investigación científica (pp. 85-101). Buenos Aires: Consejo Latinoamericano de Ciencias Sociales.

Oliveira, R. P. (2009). A transformação da educação em mercadoria no Brasil. Educação \& Sociedade, 30(108), 739760. https://doi.org/10.1590/S0101-73302009000300006

Pinheiro, D. C. F. (2014). Educação sob controle do capital financeiro: o caso do programa nacional do livro didático (Dissertação de mestrado não publicada). Universidade Federal do Rio de Janeiro, Rio de Janeiro, RJ.

Reis, L. F. (2016). Dívida pública, política econômica e o financiamento das universidades federais nos governos Lula e Dilma (2003 - 2014). Universidade e Sociedade, 57, 16-35. Recuperado de http://portal.andes.org.br/ imprensa/publicacoes/imp-pub-141512924.pdf 
Sampaio, H. (2014). Diversidade e diferenciação no ensino superior no Brasil: conceitos para discussão. Revista Brasileira de Ciências Sociais, 29(84), 43-55. https:/ doi.org/10.1590/S0102-69092014000100003

Santos, A.V., Guimarães-Iosif, R.M., \& Chaves, V.L. (2013). Formação dos oligopólios na educação superior privada brasileira: sobreimplicação no trabalho docente. Revista Educação em Questão, 46(32), 75-97. Recuperado de https://periodicos.ufrn.br/educacaoemquestao/article/viewFile/5123/4101

Seixas, P. S. (2014). A formação graduada em Psicologia no Brasil: reflexão sobre os principais dilemas em um contexto pós-DCN (Tese de doutorado). Universidade Federal do Rio Grande do Norte, Natal, RN.

Serafim, M. P. (2011). O processo de mercantilização das instituições de educação superior: um panorama do debate nos EUA, na Europa e na América Latina. Avaliação (Campinas), 16(2), 241-264. https://doi.org/10.1590/S1414-40772011000200002

Silva, R. N. (2005). A invenção da psicologia social. Petrópolis, RJ: Vozes.

Sudbrack, E. M., \& Negro, A. (2016). Internacionalização e Educação: impactos nas políticas educacionais. RP3-Revista de Pesquisa em Políticas Públicas, 1(7), 44-57. https://doi.org/10.18829/rp3.v0i1.18620

Tavares, P. H. S. (2014). Os fundos de investimentos e o movimento do capital no ensino superior privado: mercantilização de novo tipo? (Dissertação de mestrado não publicada). Universidade Federal do Rio de Janeiro, Rio de Janeiro, RJ.

Verhine, R. E., \& Freitas, A. A. S. M. (2012). A avaliação da educação superior: modalidades e tendências no cenário internacional. Ensino Superior Unicamp, 3(7), 16-39. Recuperado de https://www.revistaensinosuperior.gr.unicamp.br/artigos/a-avaliacao-da-educacao-superior-modalidades-e-tendencias-no-cenario-internacional

Whitney University System, \& Anima Educação. [s. d.]. Recuperado de http://www.mzweb.com.br/anima/web/ default_download.asp?NArquivo=ANIM3_FR_Apresentacao_20141219_PORT.pdf\&arquivo=25B4FE63-345A-4740-BA0F-B51300AEC15A

Yamamoto, O. H. (2012). 50 anos de profissão: responsabilidade social ou projeto ético-político? Psicologia: Ciência e Profissão, 32(spe), 6-17. https://doi.org/10.1590/S1414-98932012000500002

\section{João Paulo Macedo}

Professor dos Programas de Pós-Graduação em Psicologia e em Políticas Públicas da Universidade Federal do Piauí, Parnaíba-PI. Brasil. Mestre e Doutor em Psicologia pelo PPgPsi da Universidade Federal do Rio Grande do Norte, Natal - RN. Brasil.

E-mail: jpmacedo@ufpi.edu.br

\section{Marta Savana de Sousa Lima}

Aluna do Curso de Psicologia da Universidade Federal do Piauí, Parnaíba-PI. Bolsista de Iniciação Científica. E-mail: marthasavana@gmail.com.

\section{Candida Dantas}

Professora do Programa de Pós-Graduação em Psicologia da Universidade Federal do Rio Grande do Norte, Natal-RN. Brasil. Mestre e Doutora em Psicologia pelo PPgPsi da Universidade Federal do Rio Grande do Norte. E-mail: candida.dantas@gmail.com.

\section{Magda Dimenstein}

Professora Titular do Programa de Pós-Graduação em Psicologia da Universidade Federal do Rio Grande do Norte, Natal-RN. Brasil. Doutora em Saúde Mental pelo Instituto de Psiquiatria da (UFRJ).

E-mail:mgdimenstein@gmail.com. 
Endereço para envio de correspondência:

Universidade Federal do Piauí, Campus Ministro Reis Velloso, Departamento de Psicologia. Av. São Sebastião, 2819. Reis Veloso. 64202-020 - Parnaíba, PI - Brasil. Telefone: (86) 33235418.

Recebido 21/11/2016

Reformulado 20/06/2017

Aprovado 03/08/2017

Received $11 / 21 / 2016$

Reformulated $06 / 20 / 2017$

Approved 08/03/2017

Recibido 21/11/2016

Reformulado 20/06/2017

Aceptado 03/08/2017

Como citar: Macedo, J. P., Lima, M. S. S., Dantas, C., Dimenstein, M. (2017). Transnacionalização do ensino superior: impactos nos processos formativos em Psicologia no Brasil. Psicologia: Ciência e Profissão, 37(4), 852-868. https://doi.org/10.1590/1982-3703004272016

How to cite: Macedo, J. P., Lima, M. S. S., Dantas, C., Dimenstein, M. (2017). The transnationalization of higher education: the impacts in the formative process in Psychology in Brazil. Psicologia:Ciênciae Profissão, 37(4), 852-868. https://doi.org/10.1590/1982-3703004272016

Cómo citar: Macedo, J. P., Lima, M. S. S., Dantas, C., Dimenstein, M. (2017). Transnacionalización de la enseñanza superior: impactos en los procesos formativos en Psicología en Brasil. Psicologia:Ciência e Profissão, 37(4), 852-868.. https://doi.org/10.1590/1982-3703004272016 